\title{
JUÍZOS E NORMAS \\ PARA UMA FENOMENOLOGIA DOS ACTOS TÉTICOS E DOS ACTOS NOMOTÉTICOS
}

\author{
PEDRO M. S. ALVES
}

Universidade de Lisboa

Faculdade de Letras

Centro de Filosofia

psalves2@gmail.com

\section{Received:03.07.20 I4; Revised:10.02.20 I5; Accepted:I I.03.20I5}

Resumo: Discuto, de um ponto de vista fenomenológico, a distinção entre asserções e normas. Sublinho os limites da análise canónica husserliana para dar uma correcta descrição do sentido e conteúdo da intencionalidade normativa. Baseado em algumas ideias de Kelsen, traço uma distinção clara entre juízos e normas, criticando algumas tendências que provêm do próprio Husserl, as quais consideram as normas como uma intencionalidade fundada em actos objectivantes. No entanto, tomando distância relativamente a Kelsen, Kaufmann e Cossio, enfatizo que a proposição de dever (Sollsatz) não pode ser uma boa transcrição do conteúdo de sentido das normas, baseado na distinção fenomenológica entre a matéria intencional e a qualidade dos actos intencionais. Finalmente, proponho a minha própria explicação, baseada no conceito de 'força ductiva'. Mostro que há, mesmo dentro da esfera jurídica, uma variedade de forças ductiva, que vão da simples coerção até conselho e a recomendação. Para terminar, sublinho a centralidade do conceito de "força ductiva" para uma fenomenologia do mundo social.

Palavras-chave: Fenomenologia do Direito, Actos téticos, Normas, Força Ductiva

Abstract: I discuss, from a phenomenological point of view, the distinction between
judgments and norms. I stress the limits of the husserlian canonical analysis in order to
rightly account for the sense and content of normative intentionality. Based on some
Kelsian insights, I draw a clear distinction between judgments and norms, criticizing
some classical trends coming from Husserl himself that consider norms as a kind of
intentionality founded upon objectifying acts. However, taking distance from Kelsen,
Kaufmann, and Cossio, I stress that the ought-proposition (Sollsaty) cannot be a good
rendering of the sense-content of norms, based on the phenomenological distinction
between the intentional matter and the quality of intentional acts. Finally, I propose my

Manuscrito - Rev. Int. Fil., Campinas, v. 38, n.1, pp. 167-205, jan.-jun. 2015. 
own account based on the concept of 'ductive force'. I stress that the ductive force of norms cannot be identified with simple coercion. I show that there is, even inside the juridical sphere, a variety of ductive forces, going from sheer coercion to council and recommendation. Finally, I stress the centrality of the concept of "ductive force" for a phenomenology of the social world.

Key-words: Phenomenology of Law, Thetic acts, Norms, Ductive force

\section{Preâmbulo}

A fenomenologia é um instrumento de análise das configurações de sentido que possibilitam a consciência de objectos. $\mathrm{O}$ seu ponto de partida não é uma interrogação sobre o que são os objectos de que temos experiência, mas, regressivamente, sobre como se realiza a experiência de objectos. A primeira interrogação é ontologicamente orientada. A segunda suspende todo e qualquer conhecimento acerca de quaisquer domínios positivos de objectividade para se interrogar sobre como e através de que tipo de configurações de sentido temos acesso a objectos, justamente todos os que estão aí para nós, na actividade prática ou na teórica, e cuja presença aceitamos como óbvia.

Assim, tipicamente, uma pergunta fenomenológica na esfera da normatividade não será: “Que é uma norma?”, esperando, de seguida, que a ciência positiva das normas nos possa dar uma resposta. A pergunta tipicamente fenomenológica será antes: "Como se descreve a consciência de norma quanto ao seu sentido?", "Que é visar algo como norma ou através de uma norma?" Ou seja, a fenomenologia interessarse-á por descrever o sentido da experiência normativa, sentido pelo qual diferenciamos as normas de outros objectos, neste caso, de outros objectos da esfera linguística, pois a norma exprime-se em certo tipo de frases, e de outros objectos da esfera social, pois a norma tem que ver

Manuscrito - Rev. Int. Fil., Campinas, v. 38, n.1, pp. 167-205, jan.-jun. 2015. 
com agentes e acções no contexto da sociabilidade e de uma comunidade.

Para este fim, a fenomenologia tem pelo menos dois procedimentos metódicos relevantes. São eles:

1. A descrição do sentido dos actos intencionais;

2. A regressão dos actos intencionais, e dos objectos neles constituídos, até um horizonte de pré-doação.

O primeiro procedimento culmina numa teoria da constituição; o segundo tem que ver com uma teoria da génese. A relação entre ambos consiste, basicamente, no seguinte: os objectos constituídos em actos intencionais assentam num horizonte prévio, que está pressuposto nesses actos, mas que só indirectamente, por uma análise regressiva e genética, pode ser posto a descoberto. No caso vertente, uma teoria fenomenológica da constituição dirá respeito aos actos intencionais em que as normas se constituem enquanto tais; o fundo passivo dirá respeito à tessitura de sentido que está já pressuposta para que, por sobre ela, possa sobrevir algo como uma consciência normativa. Esse pressuposto da constituição de normas diz respeito aos elementos que têm já de estar pré-dados para que um objecto como uma "norma" possa fazer sentido. Este estrato pré-dado não esgota o objecto que se constitui por vida dos actos intencionais, pois, de outro modo, os actos não seriam verdadeiramente constituintes, mas apenas explicitadores; ele é, digamos, uma condição necessária, mas não uma condição suficiente para a espontaneidade activa em que as normas se constituem.

No seu trabalho de habilitação, Gesetz, und Sittengesetr, Herbert Spiegelberg distinguiu 16 sentidos do termo "norma" (1935, 64-67). A desambiguação de um termo é essencial para uma disciplina que tem na

Manuscrito - Rev. Int. Fil., Campinas, v. 38, n.1, pp. 167-205, jan.-jun. 2015. 
descrição das estruturas de sentido o seu trabalho fulcral. De todos eles, interessa-me o sentido primitivo de norma como "padrão", que é também o seu sentido etimológico, pois norma significava o ângulo recto que os carpinteiros usavam na construção, e a norma como prescrição mais ou menos autoritativa para a regulação de comportamentos na esfera individual, social e comunitária. As normas jurídicas são apenas um caso particular de um fenómeno normativo mais vasto. Há normas que regulam o manejo de instrumentos, ou o comportamento dentro de um espaço funcional, como um hospital ou um elevador; há normas éticas, religiosas, sociais, ao lado das normas estritamente jurídicas. Por todo o lado, assumiremos que a consciência normativa permanece invariante nas suas estruturas e no seu teor, pese embora a especificidade da normatividade jurídica, ligada a fenómenos que não lhe são exclusivos, como é o caso da sanção (as normas religiosas, por exemplo, prevêem também sanções que são válidas no seu universo de sentido, como a danação eterna para o pecador), ou a fenómenos exclusivos, como os mecanismos processuais, estatais, da imputação e da decisão de culpabilidade, ou o carácter coercivo, autoritativo, das suas prescrições. Tudo isso faz da intencionalidade normativa jurídica um fenómeno mais complexo, mas não genericamente diferente das outras espécies de normatividade. Introduzirei também um outro sentido de norma, a saber, o de ela ser originariamente instituidora de estatutos, instituição que é instrumental para a sua função reguladora: a norma só regula as acções e o comportamento dos agentes na medida em que os categoriza, na medida em que faz valer agentes e acções como tal ou tal. "Cidadão", "deputado", "menor", "casado" - tudo isso são estatutos para agentes; "furto", "homicídio", "acto de tomada de posse", "decisão judicial” tudo isso são categorizações para acções entre agentes, e para acções que, muitas delas, não poderiam sequer existir sem essas instituições de sentido. 
O que se segue está escorado nas seguintes decisões de base, as quais não pretendo classificar propriamente como teses. Nomeadamente,

$1^{\circ}$ Que há uma diferença irredutível entre julgar e normar;

$2^{\circ}$ Que as normas não são adequadamente expressas, no seu conteúdo e na sua validade, quando são traduzidas em proposições com o sintagma verbal "dever-ser";

$3^{\circ}$ Que a qualidade dos actos normativos é, em geral, não a obrigatoriedade, mas o que chamarei função ductiva, que pode ir da coerção estrita até à simples inclinação ou mesmo à ineficácia;

$4^{\circ}$ Que a função normativa está intencionalmente dirigida para a motivação de comportamentos, e actua como um padrão de referência, com força variável, entre uma multiplicidade aberta de outras motivações.

O primeiro ponto, que desenvolverei expressamente neste artigo, tem por base a diferenciação, de raiz husserliana, entre matéria intencional, que diz respeito ao conteúdo proposicional, e qualidade de acto, que identifica a espécie de acto intencional que reveste um conteúdo proposicional. A diferença maior é entre actos que simplesmente se referem a estados de coisas através de um conteúdo proposicional, e actos que explicitam uma tomada de posição relativamente ao próprio conteúdo proposicional. Os primeiros expressam-se em simples asserções, como "O tinteiro está cheio"; os segundos, expressam-se por meio de cláusulas que exprimem uma tomada de posição, como, por exemplo, "eu creio" ou "eu desejo que o tinteiro esteja cheio". Argumentarei que a tese de Husserl sobre os 
actos intencionais fundantes e fundados é uma base demasiado estreita para descrever a especificidade da intencionalidade normativa.

O segundo ponto, que também exporei aqui, discute a questão de saber se as normas são adequadamente expressas em proposições jurídicas usando o sintagma verbal dever-ser. Esse sintagma pode bem pertencer ao conteúdo proposicional de uma norma. A questão é, porém, outra. Trata-se de saber se a frase normativa, ao converter-se numa proposição jurídica, ou seja, numa frase declarativa que a descreva adequadamente, tem de, necessariamente, ser uma proposição de dever. A minha ideia é que a palavra "dever" se torna polissémica e não exprime verdadeiramente a validade da norma. Discutirei isto apelando para a separação entre matéria e qualidade de acto, que revê a teoria brentaniana do duplo juízo, argumentando que essa descrição não só funde o dever-ser copulativo e o dever-ser da qualidade do acto normativo, como também parte do pressuposto inadequado de que todas as normas têm uma força estritamente coerciva.

O terceiro ponto, de que farei uma apresentação meramente preliminar, introduz um termo novo para designar a qualidade de acto normativo, recusando que essa qualidade possa ser descrita, como comummente acontece, como uma ordem, um comando ou uma volição. Usarei os termos ducção e força ductiva para denominar a qualidade do acto normativo. O objectivo é contornar a equação estrita, muito vulgar na teoria das normas jurídicas, entre norma e obrigatoriedade. Direi que a qualidade do acto ductivo pode declinar-se numa gradação que vai da coerção estrita até o simples conselho, e que essa qualidade ductiva nada tem que ver com os functores deônticos, que actuam ao nível do conteúdo proposicional, os quais podem falar de permissões, de obrigações ou de proibições com uma força ductiva variável. A ideia de fundo é a que a norma é um padrão de referência para a motivação de comportamentos que tem um impacto variável

Manuscrito - Rev. Int. Fil., Campinas, v. 38, n.1, pp. 167-205, jan.-jun. 2015. 
sobre a sua liberdade: a força ductiva da norma pode ir da coercividade pura até a simples recomendação ou ao conselho.

Finalmente, o quarto ponto, que apenas mencionarei ocasionalmente, tem por base a ideia de que os objectos intencionais dos actos normativos não são os comportamentos factuais dos agentes, mas as suas decisões, e que a norma actua como um ponto de referência, e como uma razão mais ou menos forte no plexo de motivações que determinam um comportamento. A ideia de fundo é que a norma, que intencionalmente se dirige às decisões, é ela própria uma decisão da autoridade normativa, de tal modo que, se olharmos não para a relação estática de subsunção entre normas positivas e comportamentos, mas para o dinamismo da intencionalidade normativa, encontraremos uma relação entre decisões do legislador, decisões dos agentes, e mesmo, quando é o caso, decisões de tribunais, agentes que podem ser indivíduos, categorizados pelos conceitos normativos, ou sujeitos de ordem superior, como instituições e entidades colectivas. A opção de Reinach de substituir o termo "norma" por "Bestimmung" mostra, parcialmente, este fundo decisório da normatividade, pois Bestimmung contém uma constelação de sentidos que andam em torno das noções de determinação, destinação e disposição.

\section{I - Actos téticos e actos nomotéticos: dois domínios irredutíveis}

Não há, até o presente, uma análise fenomenológica suficientemente desenvolvida acerca da consciência normativa. Não há, sequer, uma visão consensual, estável, a respeito do que seriam, para essa análise, os instrumentos conceptuais pertinentes.

Isto tem que ver com a orientação predominante da fenomenologia para o estudo dos actos téticos, ou seja, para o estudo

Manuscrito - Rev. Int. Fil., Campinas, v. 38, n.1, pp. 167-205, jan.-jun. 2015. 
daquelas formas de intencionalidade que são intenções de ser - Seins"setzende" Akte, "thetische" (Husserl, 1977, 256) - e que aprendem, portanto, o seu objecto sob uma qualquer modalidade posicional, seja ela a existência, a possibilidade, a não-existência ou outra. De facto, foi em torno dos actos téticos - a que Husserl chamou, na quinta investigação lógica, actos objectivantes - que a análise fenomenológica da intencionalidade adquiriu os seus instrumentos conceptuais basilares e as suas teses mais cruciais. Nomeadamente, os conceitos de matéria intencional - nominal ou proposicional - e de qualidade de acto, bem como a tese, que resulta de uma releitura crítica de um célebre dictum de Brentano, de que, entre as várias qualidades de acto que uma análise fenomenológica pode distinguir, seriam os actos objectivantes que deteriam o estatuto de forma fundante da intencionalidade, no sentido de que qualquer acto intencional seria ou um acto objectivante ou teria um acto objectivante como sua base.

Assim despontou a ideia de uma hierarquia entre as formas de intencionalidade, à luz da qual qualquer qualidade de acto nãoobjectivante, como o desejar, o querer, o valorar, etc., pressuporia, "na sua base", um acto de qualidade objectivante, estaria nele fundada, ao passo que o acto objectivante não careceria de qualquer outro acto para se efectivar. Chamarei a esta tese de Husserl a "hierarquia-padrão" dos actos intencionais, a qual remonta, seguramente, a Brentano, embora com uma diferente caracterização.

Esta tese é verosímil em casos como os dos actos optativos ou volitivos. Assim, a frase "desejo que sirvam bolinhos com o café", que dá expressão a um acto de qualidade optativa, teria por base um acto objectivante que poria o estado de coisas descrito na matéria proposicional "há bolinhos com o café" como possível, possibilidade essa que serviria de base para o subsequente acto de desejo. 
Como estender, porém, esta análise para os actos nomotéticos ou normativos? Sejam frases como "O homicídio é punido com pena de prisão de 8 a 16 anos" (Artigo 131 do Código Penal) ou "O PrimeiroMinistro é nomeado pelo Presidente da República" (Constituição da República Portuguesa, Artigo $\left.187^{\circ}, \mathrm{n}^{\circ} 1\right)$. Tomemo-las não como frases declarativas que descrevem uma ordem jurídica positiva, precedidas de locuções como "O Artigo $131^{\circ}$ do Código Penal diz que...", frases que podem ser verdadeiras ou falsas, mas como normas que instituem a própria ordem jurídica que as frases declarativas, de seguida, descrevem. Tomemo-las, portanto, como expressão de actos nomotéticos, que não se referem a normas pré-existentes, mas que as instituem originalmente.

Qual o acto objectivante que está na sua base? A resposta é, obviamente, a seguinte: o acto nomotético que institui essas normas não contém qualquer acto tético subjacente. E isso por três razões.

Primeiro, a norma constitucional que acabei de transcrever não tem por base a descrição de um estado de coisas pré-existente - pelo contrário, institui-o, pois ela não assenta na posição prévia do acto de nomeação como possível ou como real, mas é ela que cria originalmente tal possibilidade: não houvesse normas instituindo certos estatutos e funções, não haveria sequer algo como um Presidente e um Primeiro-Ministro, a propósito dos quais certas frases declarativas verdadeiras são, de seguida, possíveis. $\mathrm{Na}$ verdade, o acto normativo tem certamente um pensamento director. Neste caso, a relação de nomeação entre dois actores institucionais. Mas esse pensamento não se articula sob qualquer modalidade posicional, não visa o seu objecto como um facto, possível ou real. Ele é simplesmente o sentido do acto normativo e não um elemento de um acto tético, posicional. A prova última é que, se fizéssemos abstracção sistemática de todos os objectos constituídos em actos normativos, nada ficaria que pudesse ser objecto

Manuscrito - Rev. Int. Fil., Campinas, v. 38, n.1, pp. 167-205, jan.-jun. 2015. 
de um acto tético, ou seja, de um acto que visasse o seu objecto sob uma qualquer modalidade de ser. Ficariam seguramente as pessoas envolvidas, nas suas dimensões físicas e morais; no entanto, não haveria já algo como um Presidente, um Primeiro-Ministro, e um acto institucional cujo sentido seria a nomeação. Não restaria, portanto, nada que um acto tético pudesse visar antes de a função normativa ter constituído os seus objectos, razão pela qual o acto normativo não tem, notoriamente, um acto objectivante na sua base; pelo contrário, é ele que torna possível a existência de tais actos, relativamente aos objectos que originariamente institui.

Para ir direito ao ponto essencial, direi que, em geral, um acto de uma qualidade qualquer está (mediata ou imediatamente) fundado sobre um acto de base de qualidade objectivante se o acto dito fundado (i) conservar a qualidade posicional do acto de base e (ii) contiver, pelo menos como uma sua parte, a sua matéria intencional. Assim, o juízo de valor "é uma expressão de reprovável gulodice desejar bolinhos com o café" está, obviamente, mediatamente fundado no acto objectivante "é possível que haja bolinhos com o café", pois, em primeiro lugar, conserva a modalidade posicional do acto de base (aqui, a consciência de uma possibilidade) e, em segundo lugar, contém a matéria intencional do acto fundante como parte da matéria intencional do acto fundado total, acrescentando-lhe outros estratos de sentido: "é possível que haja bolinhos" (acto objectivante), "desejo que haja bolinhos" (acto optativo), "desejar bolinhos com o café é uma expressão de gula" (acto objectivante), "a gulodice é reprovável" (acto valorativo). Esta análise não é, porém, transferível para as normas. Dir-se-á, porventura, que a norma "o homicídio é punido, etc." pressupõe o acto objectivante de base "há condutas homicidas". Ora isto não é sustentável. Desde logo, porque a norma não afirma nem nega a existência real de actos homicidas e, a limite, poderia mesmo nunca suceder a situação para a qual a norma prescreve uma punição. Mesmo num mundo já sem 
homicídios, como factos reais, a norma continuaria a prescrever aquele acto punitivo preciso e não seria afectada na sua validade - uma norma que não encontra aplicação nem por isso deixa de ser (apesar de supérflua) uma norma. Replicar-se-á, porventura, que a norma prevê o homicídio pelo menos como uma conduta possível, e que essa consciência de possibilidade é um acto objectivante? Mas nem isso se revela correcto numa análise mais fina. Primeiro, porque não há homicídios, como factos, antes de uma norma prescritiva os ter assim categorizado, estatuindo que, em certas condições, que uma pessoa morra por acção ou omissão de uma outra é classificado como homicídio. O homicídio não é um facto real - é o resultado de uma categorização normativa incidindo sobre factos reais. Essa categorização não é, ela própria, um acto objectivante - é uma imputação sob a forma "isto (um acontecimento efectivo) é um homicídio", ou seja, cai sob o conceito jurídico de homicídio, imputação que depende, por sua vez, de uma norma que define o que se deve entender por "homicídio". Ora, em segundo lugar, a norma punitiva incide sobre a matéria da norma definidora de homicídio e estatui que a situação que juridicamente se define como um acto de homicídio é punida de tal ou tal modo. Para os actos normativos, na sua concatenação, a relação das situações jurídicas com factos, e com os actos objectivantes que os descrevem, é inessencial. A norma que prescreve a punição do homicídio envolve a norma que define o que seja um homicídio. Mas saber se o conceito jurídico de homicídio se aplica ou não a qualquer comportamento efectivo ou possível de pessoas reais é algo que está já de fora da esfera normativa. Essa parte diz respeito à imputação, pela qual se decide se, em condições determinadas, que alguém tenha morrido por acção ou omissão de outrem conta ou não como uma conduta que a norma caracteriza como homicida. Toda imputação pressupõe um acto objectivante, certamente. Mas a norma é independente dele, pela tripla razão de que a norma se move numa esfera de idealidade conceptual ("homicídio", 
"punição", etc.), de que é ela que institui as situações a que os actos objectivantes se referem, e de que, no limite, a norma continuaria a valer como tal mesmo se, na realidade, por razões circunstanciais ou permanentes, não houvesse mais quaisquer factos (visados nos actos objectivantes correspondentes) a que os conceitos normativos se pudessem aplicar. Com certeza que os actos normativos se combinam com os actos objectivantes, na medida em que a esfera normativa percorre os factos e as possibilidades do mundo social real. Mas essa relação não é uma relação de fundação, no sentido estrito que acima indicamos: a norma sancionatória "o homicídio é punido..." está fundada na norma instituidora "homicídio é a situação em que..." e não no acto objectivante "há homicídios" ou "é possível que haja homicídios", pois que haja ou possa haver isso é algo que está dependente da norma que categoriza factos do mundo real como situações desse tipo; saber se haverá factos no comportamento dos indivíduos que possam cair sob o conceito jurídico de homicídio ou outro será, por certo, importante para avaliar da pertinência e da sageza de uma norma - não é, porém, um ingrediente fundante do acto normativo, no sentido de a norma ter de conter a qualidade posicional ou a matéria intencional do acto objectivante correlacionado. ${ }^{1}$

Segundo, voltando ao exemplo da norma constitucional, ela não é nem verdadeira nem falsa, como será verdadeiro ou falso que deseje bolinhos com o café ou que seja possível haver bolinhos com o café - a norma só pode ser ou válida ou inválida: certas coisas acontecem

\footnotetext{
${ }^{1}$ Dir-se-á que, pelo menos, a norma que prescreve uma sanção se baseia no juízo de valor que classifica a conduta em causa como "má", "reprovável", ou que a norma se baseia em juízos morais do tipo "não se deve matar", e que estes serão actos objectivantes? Direi, aqui, que, por um lado, "não se deve matar" 'é já uma norma e que, por outro, de um juízo de valor, que descreve a qualidade axiológica de um estado-de-coisas, não se pode derivar a forma prescritiva da norma. Este assunto será abordado com mais detalhe na próxima secção.
}

Manuscrito - Rev. Int. Fil., Campinas, v. 38, n.1, pp. 167-205, jan.-jun. 2015. 
porque a norma é válida, coisas que são interpretadas à luz da própria norma, por exemplo, como um acto de nomeação, ou então nada acontece, porque a norma é inválida, ou seja, não existente, ou porque a sua força ductiva não é coerciva, ou porque, apesar de coerciva, não é eficaz.

Terceiro: à norma não se aplica o princípio lógico tertium non datur - enquanto o contrário de uma proposição falsa é verdadeiro, e inversamente, o contrário de uma norma válida não é eo ipso uma norma inválida. Por exemplo, enquanto da verdade da proposição "desejo que haja bolinhos com o café" se segue a falsidade da proposição contrária, "não é o caso que deseje bolinhos com o café", da validade de uma norma não se segue que não exista uma norma contrária que seja também válida. Para os actos objectivantes, e também para os actos fundados, disjunções lógicas como "Ou há bolinhos com o café ou não há bolinhos com o café” são sempre verdadeiras. As normas têm um comportamento assaz diferente; o predicado da validade qualifica todas as normas existentes num sistema normativo qualquer. A tese kelsiana equacionando validade e existência, no caso das normas, pode ser subscrita mesmo por uma visão não estritamente positivista do Direito. De facto, é óbvio que, para um candidato a norma, o reconhecimento da sua invalidade é o reconhecimento da sua nulidade, ou seja, da não existência dessa frase prescritiva dentro de um sistema normativo. Para uma norma, invalidade é inexistência e existência é validade. Assim, se uma norma $\mathrm{N}$ é válida, daí não se segue que não exista uma norma conflituante; e, se não existe uma qualquer norma $\mathrm{N}$, não se poderá inferir que exista a norma contrária $\sim \mathrm{N}$. Uma frase declarativa sobre a validade ou não validade de uma norma está governada pelo princípio do terceiro excluído. Mas a própria norma não está: das normas $\mathrm{N}$ e $\sim N$, não se poderá dizer que só uma existe (é válida), ou que a existência (validade) de uma exclui a existência da outra: podem ser ambas válidas (existentes) ou ambas inválidas (não existentes). Assim,

Manuscrito - Rev. Int. Fil., Campinas, v. 38, n.1, pp. 167-205, jan.-jun. 2015. 
normas conflituantes existem, sem que a validade de uma delas fique, desde logo, anulada pelo próprio conflito. ${ }^{2}$ Uma frase declarativa pode existir sem ser verdadeira; uma norma não pode existir sem ser válida. Como escreveu Amedeo Conte a propósito das teses da fase última de Kelsen, "Tal como, de duas frases descritivas contraditórias, uma é necessariamente não-verdadeira (falsa), assim também uma de duas frases prescritivas contraditórias pareceria ser necessariamente inválida. No entanto, ... o princípio ... não tem aplicação directa ou indirecta à validade das frases prescritivas. ... Se há duas frases prescritivas contraditórias num sistema normativo, então ambas existem nesse sistema, o que é o mesmo que dizer (de acordo com a equação kelsiana de validade e existência) que serão ambas válidas. O princípio de nãocontradição não se aplica, portanto, directamente à validade (existência) das frases prescritivas" (Conte, 1998, 332).

O dictum de Brentano, na sua reformulação husserliana, parece, pois, não ter aqui aplicação: não só os actos nomotéticos parecem não envolver actos téticos subjacentes, mas antes os possibilitarem, como também parecem não ser convertíveis neles: nada nas normas tem o teor de uma frase descritiva, nada nelas pode ser dito verdadeiro ou falso, nada nelas obedece a princípios lógicos válidos para as frases

\footnotetext{
${ }^{2}$ As teses mais amadurecidas de Kelsen vão justamente neste sentido, que revê algumas teses das suas obras anteriores. Por exemplo, "The conflict between norms presupposes that both norms are valid. The assertions concerning the validity of both conflicting norms are true. Therefore, a conflict between norms is not a logical contradiction and cannot even be compared to a logical contradiction. Derogation repeals the validity of one of the valid norms. But in case of a logical contradiction between two assertions, one of the two assertions is untrue from the very beginning. Its truth is not repealed for it does not exist at the outset. Since the validity of a norm is its own specific existence, a conflict between norms cannot be compared to a logical contradiction" (Kelsen, 1973, 271). Nesta fase, Kelsen afasta a ideia que uma norma possa, por si própria, ter força derrogante face a outra norma relativa à mesma conduta, segundo o princípio lex posterior derrogat priori (Kelsen, 1973, 236).
}

Manuscrito - Rev. Int. Fil., Campinas, v. 38, n.1, pp. 167-205, jan.-jun. 2015. 
declarativas, como o princípio de não-contradição e do terceiro excluído. Pelo contrário, as normas parecem estar ao mesmo nível dos actos téticos e serem um seu conjunto complementar. Juízos e normas parecem, pois, ocupar em conjunto o campo husserliano dos actos fundantes.

O reconhecimento, implícito ou explícito, desta ausência de uma base tética para os actos normativos determina, em vários autores, uma opção teórica que consiste, grosso modo, no seguinte: dado que as normas não parecem exibir um fundo tético, socorramo-nos, então, da vetusta oposição kantiana entre ser e dever-ser (entre Sein e Sollen) e construamos o plano normativo como expressão da esfera paralela do "dever-ser". Esta cisão entre dois domínios ontológicos, como base para a separação entre juízos e normas, foi, como é sabido, a orientação permanente de Kelsen. Mas também um seu discípulo, o fenomenólogo Felix Kaufmann, afirma que o dever-ser, ao lado de pessoa e de comportamento, conta como um dos conceitos fundamentais do Direito. $^{3}$

\section{II - Sobre a dependência do acto normativo}

Se perguntarmos, agora, qual seja a qualidade destes actos nomotéticos, que não exibem um fundo tético, a hierarquia-padrão parece também não poder sugerir uma resposta satisfatória. De facto, esta hierarquia-padrão só discrimina tipicamente actos de qualidades como a volitiva, a optativa, a imperativa, a estimativa ou a emotiva (Gemütsakte), e refere-as a todas a actos téticos subjacentes. Daí resulta

3 „Diese Rechtsbegriffe müssen sich sämtliche aus den Rechtsgrundbegriffen gewinnen lassen, den sachhaltigen Begriffen des reinen, eifachen Rechtssatzes. Als solche haben wir den Begriff des Menschens, welchen wir in seiner rechtlichen Apriorisierung als Person bezeichnen wollen, den Begriff des Verhaltens und endlich den Begriff des ,Sollens' erkannt." (Kaufmann, 1922, 102).

Manuscrito - Rev. Int. Fil., Campinas, v. 38, n.1, pp. 167-205, jan.-jun. 2015. 
uma tendência para dissolver a qualidade específica do acto nomotético numa mistura, mais ou menos imprecisa, de actos imperativos, volitivos, valorativos e mesmo téticos, como se uma norma se pudesse analisar, quanto à sua qualidade de acto, por uma amálgama de juízos teóricos, de valor, de comandos e de volições.

Uma clara ilustração deste caminho é a passagem dos Prolegómenos à Lógica Pura em que Husserl remete o acto normativo para actos valorativos e teóricos subjacentes (1975, 53 e sgs). Um dos exemplos é o da norma "Um guerreiro deve ser corajoso", norma que contém, na sua matéria intencional, a expressão "deve-ser", como se isso fosse o carácter distintivo da normatividade, e que, do ponto de vista da qualidade, Husserl apresenta como sendo um comando ou uma exigência objectiva, se bem que não uma ordem, dada por alguém a um destinatário preciso. A tese desenvolvida no passo em questão é que essa norma está fundada no juízo de valor "Só um guerreiro corajoso é um bom guerreiro"; juízo de valor que, por sua vez, se bem interpreto, estaria fundado na lei de essência "Todo guerreiro autêntico é corajoso", lei que não diz o que são ou não os guerreiros de facto, mas o que tem de ser um guerreiro para que possa ser plenamente apelidado de tal, descrevendo, assim, de uma maneira puramente teorética, a conexão apriorística entre a ideia de guerreiro e o predicado da coragem. Husserl precisa, mais adiante, que este núcleo teórico poderá ser expresso, independentemente de toda a normatividade, pelo juízo "Só um A que é B tem a qualidade C", em que C designa a propriedade que a subsequente valoração fundamental descreve, para cada região ôntica em concreto, como a circunstância de "ser um bom A".

Assim se desenha uma tese a que chamarei a "tese da dependência”. Esta tese parece outorgar às normas aquele fundo tético que não era antes visível. Ela estatui que, para justificar uma norma, construída na sua matéria intencional com o sintagma verbal "deve- 
ser", teremos de encontrar o juízo de valor e o juízo teórico antecedentes, juízo teórico que, pelo seu lado, exprimiria uma lei pura de essência, anterior a quaisquer factos. Assim, a esfera normativa seria um campo de comandos ou imperativos assente num plano axiológico e num plano teorético mais fundamentais, campo para o qual poderia ser dada a seguinte fórmula de derivação: do juízo tético "Só um A que é B tem a qualidade C", segue-se o juízo de valor "só um A que tem C é um bom A", e, finalmente, o comando "A deve ser B", que prescreveria para a esfera dos factos - aqui, dos agentes e das acções -, como uma exigência objectiva a que esses factos estariam necessariamente submetidos.

Esta não é, porém, uma necessidade ôntica, que expressaria aquela conformação inexorável do facto com a sua essência de que Husserl fala, por exemplo, na Introdução de Ideias I (1977, 19-20), como é o caso na proposição "se x é um homem, então x é necessariamente mortal”; ela exprimiria, antes, uma necessidade deôntica, assente numa prescrição, a qual deixa margem para uma liberdade de decisão que pode quer ou não querer estar em conformidade com a norma, necessidade que poderia enunciar-se assim: "se $\mathrm{x}$ é um guerreiro, e se $\mathrm{x}$ quer ser um bom guerreiro, então $\mathrm{x}$ tem necessariamente de ser um guerreiro corajoso". Vê-se, porém, que esta exigência objectiva "Se queres ser um bom A, então deves ser B", não formula ainda uma obrigação para $\mathrm{x}$, ou seja, ela não contém a formulação de uma vinculação da vontade de $\mathrm{x}$ à norma estatuindo que um A deve ser B para que seja um bom A. Ela é em tudo igual à proposição "só o ouro de 24 quilates é um ouro puro (um ouro "bom")", da qual deriva: "o ouro deve ser de 24 quilates". Isto, porém, é a expressão de um dever-ser ôntico, mas não deôntico. Assim, não definindo que tipo de vinculação há entre norma e vontade de $\mathrm{x}$, a formulação husserliana da normatividade é meramente hipotética: se $\mathrm{x}$ quer ser $\mathrm{D}$, então deve querer $\mathrm{F}$, pois $\mathrm{F}$ é condição para ser $\mathrm{D}$; no

Manuscrito - Rev. Int. Fil., Campinas, v. 38, n.1, pp. 167-205, jan.-jun. 2015. 
entanto, uma cabal caracterização da norma deve ir mais longe: ela deve qualificar este "se" e definir o modo como a vontade de $\mathrm{x}$ fica vinculada, se como uma obrigação, uma sugestão, um conselho, uma recomendação, ou outra. É que isso que designaremos doravante como "força ductiva". A formulação husserliana da normatividade não a contém verdadeiramente. Ela diz que um A ("bom", "autêntico", "puro") deve ser B, mas não diz até que ponto os sujeitos a quem a norma se dirige ficam vinculados a terem de ser A. Husserl parece pensar, porém, que a força prescritiva da norma assenta, a montante dela, em juízos teóricos e em valorações, juízos teóricos e valorações que poderiam ser encontrados regressivamente como algo pressuposto no conteúdo proposicional da norma (A deve ser $\mathrm{B}$, porque só um A que é $\mathrm{B}$ tem a qualidade $\mathrm{C}$ e porque só um $\mathrm{A}$ que tem $\mathrm{C}$ é um bom $\mathrm{A}$ ).

Em substância, a questão candente tem que ver com o seguinte: a forma da normatividade não está pré-contida nem pode ser derivada de juízos téticos, sejam eles de que tipo forem. Para o ver com acuidade, bastará contrapor os juízos:

1. Só um guerreiro que é corajoso é um bom guerreiro;

2. O guerreiro deve ser corajoso;

à norma:

3. O guerreiro é corajoso.

No caso de 3., o "é" está empregue em acepção normativa ele não descreve um facto, digamos, que tal ou tal guerreiro seja corajoso; ao invés, impõe uma certa propriedade ao guerreiro, independentemente do facto de haver guerreiros e de serem ou não realmente corajosos. Ora, quando comparada com 1. e 2., a fórmula 3. contém uma qualidade de acto (a da normatividade) que é, pura e 
simplesmente, inderivável de 1., que exprime uma valoração baseada numa lei de essência, e de 2., que exprime um dever-ser ôntico. Reencontramos, aqui, a vetusta tese de Hume acerca da irredutibilidade dos juízos em ought a juízos em is.

Esta tese husserliana da dependência está repleta de consequências relativamente à autonomia da racionalidade jurídica e das ciências normativas em geral, na medida em que ela estatui que “... as suas regras têm de possuir um conteúdo teorético separável do pensamento da normatividade (do dever-ser), conteúdo cuja pesquisa científica compete precisamente àquelas disciplinas teoréticas" (Husserl, 1975, 53). De facto, a justificação destes actos, a sua racionalidade intrínseca, bem como a possibilidade de se lhes reconhecer força normativa, ou seja, poder de vincular, passaria pela possibilidade de os reconduzir aos planos axiológico e puramente teórico, supostamente mais fundamentais, e de os justificar a partir deles.

\section{III - O “dever-ser” e sua suposta função normativa}

A este propósito, quero discutir mais a fundo esta tendência persistente para descrever a norma por um juízo e para fazer a sua força normativa emergir no sentido proposicional desse juízo pelo sintagma "dever-ser". Trata-se de saber se aquilo a que Husserl chamou o "pensamento da normatividade", de onde as normas obtêm o poder de guiar os comportamentos, é algo que tem de se expressar no seu conteúdo proposicional (na sua "matéria"), assumindo quer a forma de um juízo hipotético do tipo "Se A é, então deve ser B", quer a forma de um juízo copulativo "A deve ser B". Como questão subsidiária, discutirei se este putativo "dever-ser", que expressaria a normatividade, é, por princípio, justificável apenas pelo conteúdo semântico interno da proposição normativa.

Manuscrito - Rev. Int. Fil., Campinas, v. 38, n.1, pp. 167-205, jan.-jun. 2015. 
Relativamente à primeira questão, há que reconhecer que a resposta afirmativa é quase consensual entre os autores da tradição fenomenológica. Para lá do próprio Husserl, que vê no sintagma "dever-ser" a expressão da normatividade, referirei apenas dois casos paradigmáticos. O primeiro é o do fenomenólogo Felix Kaufmann que, seguindo Kelsen, vê a origem do direito num Soll-Satz, ou seja, numa proposição de dever-ser, a qual, mais uma vez com Kelsen, envolve um juízo hipotético articulando uma norma secundária e uma norma primária:

Um sujeito A deve realizar um comportamento C1 e, se não o fizer, deverá então ter lugar, contra ele, um comportamento $\mathrm{C} 2 .{ }^{4}$

O outro caso é o do jus-fenomenólogo argentino Carlos Cossio, que, também sob o paradigma kelsiano, descreve do seguinte modo a proposição jurídica:

A análise fenomenológica do problema normativo que a egologia efectuou ... estabelece ... que a norma é um juízo e que, nesse juízo, a cópula proposicional é o verbo dever-ser e não o verbo ser. ... Dado $A$, dever ser $B .^{5}$

\footnotetext{
4 "Jeder Rechtssatz konstituiert sich als Doppelnorm in der Weise, dass das SollSubjekt der primären Norm „Zielpunkt“ des in der sekundären Norm gebotenen Verhalten wird. Der "reine eifache" Rechtssatz lautet: Ein Subjekt A soll ein Verhalten V1 an den Tag legen, tut es dies nicht, so soll ihm gegenüber ein Verhalten V2 platzgreifen" (Kaufmann, 1922, 91).

5 "El análisis fenomenológico del problema normativo que ha efectuado la Egología ... establece ... que la norma es un juicio y que en ese juicio la cópula proposicional es el verbo deber ser y no el verbo ser. ... Dado A, debe ser B" (Cossio, 1964, 332333 e 353).
}

Manuscrito - Rev. Int. Fil., Campinas, v. 38, n.1, pp. 167-205, jan.-jun. 2015. 
Relativamente à segunda questão, Adolf Reinach é, com Husserl, um claro defensor da tese segundo a qual o carácter prescritivo da norma se justifica por razões deriváveis do seu simples conteúdo proposicional. Reinach argumenta que há qualquer coisa como "configurações jurídicas" (rechtliches Gebilde) que estão governadas por leis puras de essência anteriores a qualquer norma jurídica positiva, norma que designa como uma "determinação" (Bestimmung) e que faz depender de um acto social específico. Assim, para usar o seu exemplo, a correlatividade entre promessa e obrigação é uma configuração jurídica que está baseada no próprio eidos "promessa", e é essa conexão de essência que dá o fundamento para a lei positiva determinando que os contratos devem ser cumpridos. Contrariamente aos matizes positivistas de Kaufmann, para Reinach, o direito não começa com o acto normativo; ao invés, a determinação jurídica instancia estruturas eidéticas puras que são, como escreve Barry Smith, "anteriores a qualquer convenção humana e que seriam o caso mesmo que nunca fossem actualmente reconhecidas por um qualquer sujeito pensante" (Smith, 1987, 297). ${ }^{6}$ Esta é uma clara retomada da tese da dependência de Husserl. A determinação positiva "os contratos devem ser cumpridos" pode justificar-se pela remissão para o juízo de valor "só um pacto que é cumprido é um bom pacto", e este, por sua vez, para uma configuração jurídica assente na lei material de essência "toda promessa envolve a obrigação de cumprimento" ou, dito pela negativa "uma promessa que não envolva a obrigação de cumprir não é uma promessa". Deste modo, a tese husserliana da dependência mostra-se, aqui, como directamente vinculada à ideia de que a força normativa se pode justificar pelo próprio conteúdo semântico positivo que é

\footnotetext{
${ }^{6}$ Reinach opõe-se expressamente ao positivismo jurídico, que toma a proposição jurídica como o lugar originário do Direito e a refere a uma esfera autónoma de dever-ser, doutrina que descreve pela tese segundo a qual "An sich bestehende zeitlos geltende rechtliche Gebilde, in Sinne der Mathematik, gibt es schlechthin nicht" (Reinach, 1989, 141).
}

Manuscrito - Rev. Int. Fil., Campinas, v. 38, n.1, pp. 167-205, jan.-jun. 2015. 
expresso na proposição jurídica. A obrigação nela estatuída tem um fundo tético que pode ser mediatamente exibido regredindo até o juízo teórico correspondente, de tal modo que, como escreve Reinach, "as configurações que, em geral, designamos como especificamente jurídicas possuem um ser, tal como os números, as árvores ou as casas" (Reinach, 1989, 143).

Discrepo destas duas teses, a saber, de que a dimensão normativa se tenha de expressar no conteúdo proposicional da norma pelo sintagma "dever-ser" e de que haja um fundo tético anterior às posições da intencionalidade normativa. No que se segue, quero apresentar alguns argumentos para o justificar a minha discordância sobretudo a respeito da primeira.

$\mathrm{O}$ meu primeiro argumento assenta no que me parece ser um dos pontos fortes $\mathrm{da}$ análise husserliana da estrutura $\mathrm{da}$ intencionalidade. Refiro-me à separação estrita entre matéria e qualidade, bem como à tese de que a atitude dóxica que está envolvida na asserção - no caso normal, a crença - não se reflecte no conteúdo proposicional da asserção, ou seja, na sua matéria, nomeadamente na cópula. Como é sabido, essa separação foi estabelecida através de uma crítica da doutrina brentaniana do duplo juízo. De acordo com esta, o conteúdo proposicional de um juízo "A é B" teria de ser lido como uma dupla asserção, em que o "é" exprimiria, primeiro, a crença de que a "A existe" ou de que "AB existe" (Brentano chama-lhe die Anerkennung, o reconhecimento ou admissão), e, de seguida, exprimiria a relação predicativa em sentido estrito, de tal modo que, na sua estrutura de conjunto, o juízo significaria "o A, que existe, é B" ou "o A que é B existe", dependendo do facto de a representação de base ser simples, apenas A, ou complexa, AB. Contra esta doutrina do duplo juízo, Husserl mostrou convincentemente que o "é" tem, na proposição, uma função meramente copulativa, pois nenhuma 
diferença fenomenológica há entre uma proposição, digamos, "Marte é três vezes mais pequeno que a Terra", quando é asserida como verdadeira ou quando é simplesmente considerada como uma proposição sobre a qual não tomamos posição, ou mesmo da qual descremos. De facto, se a crença e a descrença, ou qualquer outra atitude dóxica, não versassem sobre o mesmo conteúdo proposicional, teríamos então várias proposições e não apenas uma só. Ora isso significa que o "é” só pode ter uma função copulativa e que a qualidade posicional do juízo não está plasmada no seu conteúdo proposicional.

Pois bem, a tese de que a proposição jurídica contém o sintagma verbal "deve-ser" parece ser uma recaída nesta tese brentaniana, dado que implica que a qualidade normativa do acto se tenha de expressar na sua matéria proposicional. Carlos Cossio é bem ilustrativo desta mescla. Num passo da sua Teoria Egológica do Direito, escreve:

Sabemos já que o dever-ser copulativo se refere à concordância, por ele estabelecida e enunciada, entre os dois termos da norma; ao passo que o dever-ser da norma em conjunto se refere à concordância entre ela, enquanto menção de conduta, e a percepção da conduta por ela visada. $^{7}$

Numa palavra: o dever-ser estabelece uma conexão copulativa entre os termos da proposição e, ao mesmo tempo, exprime que a proposição, no seu todo, tem um valor normativo relativamente às condutas dos seus destinatários. Esta tese parece estar em retrocesso relativamente à separação estrita entre matéria e qualidade, bem como à

\footnotetext{
7 "Ya sabemos que el deber ser copulativo se refiere a la concordancia, por el establecida y enunciada, entre los dos términos de la norma; en tanto que el deber ser de la norma en conjunto se refiere a la concordancia entre ella como mención de la conducta y la percepción de la conducta por ella mentada" (Cossio, 1964, 369).
}

Manuscrito - Rev. Int. Fil., Campinas, v. 38, n.1, pp. 167-205, jan.-jun. 2015. 
evidência de que uma mesma matéria pode ser revestida por actos de diferentes qualidades permanecendo, porém, inalterada no seu estrito teor proposicional. Para voltar ao exemplo de há pouco, o conteúdo proposicional "O Presidente da República nomeia o PrimeiroMinistro" é o mesmo, seja ele expresso num acto com força assertiva ou num acto com força normativa. No primeiro caso, trata-se de uma frase declarativa que descreve, de um modo verdadeiro ou falso, um artigo da Constituição portuguesa; no segundo caso, trata-se da própria norma, que não descreve, mas determina como alguém pode ser constituído na função de primeiro-ministro. Se bem que a força, ou o que designamos como "qualidade de acto", seja totalmente diversa, o conteúdo proposicional permanece invariável. A dar crédito a Cossio, porém, o conteúdo proposicional teria de ser diferente, nomeadamente a cópula "é" da norma deveria poder ser substituída pela cópula "deve ser” na proposição jurídica, exprimindo esta, duplamente, a conexão entre os termos na proposição e a força normativa da proposição como um todo. No entanto, é claro que a norma "O Presidente nomeia o Primeiro-Ministro" não é semanticamente equivalente à proposição jurídica "O Primeiro-Ministro deve ser nomeado pelo Presidente". A norma não diz que é preferível que seja o Presidente a nomear (se admitirmos a interpretação fraca de dever); a norma também não diz que é dever do Presidente nomear (se admitirmos a interpretação forte); a norma diz, simplesmente, que há Primeiro-Ministro quando há um acto de nomeação pelo Presidente.

Além disso, o dever-ser introduzido na descrição da norma, para lá de alterar o sentido da proposição, está longe de poder expressar a força normativa. Num trabalho recente, Paolo de Lucia procedeu a uma análise da polissemia de "dever-ser" (Lucia, 2003). Distinguiu entre um sentido bulético, um sentido axiótico e um sentido eidético de dever. $\mathrm{O}$ primeiro tem que ver com desejos e volições, como quando dizemos "deves estar em casa às 3 horas", uma forma elíptica de dizer "eu quero 
que..." ou "eu ordeno-te que..." O segundo exprime uma apreciação valorativa acerca do que é bom em cada caso, que não tem necessariamente de ser desejada ou querida por alguém. Por exemplo, "O Drama não deve ser dividido em episódios", "Todo homem deve amar o seu próximo". O terceiro, o dever eidético, exprime uma necessidade de essência, como na frase "Um triângulo equilátero deverá ter os ângulos internos iguais", ou ainda na frase reinachiana " $\mathrm{Da}$ promessa deve nascer uma pretensão". Os três sentidos organizam-se a partir dos conceitos de querer, de valer e de necessidade ôntica, no sentido que lhe foi dado por Albert Hofstadter:

Temos necessidade ôntica quando ... o facto de que uma coisa seja qualquer coisa necessita que seja outra coisa, ou quando o facto de ser qualquer coisa a impede de ser uma outra coisa. ${ }^{8}$

Pace Reinach e Lucia, o "dever-ser copulativo" na proposição jurídica (Cossio, porém, refere-se verdadeiramente, com essa expressão, à relação entre os membros do juízo hipotético: "se A é, então deve ser B") não exprime uma necessidade de essência. Simplesmente descreve aquilo que a norma estatui, como quando, relativamente à norma do Código de Estrada "Quem circular em sentido oposto ao estabelecido é sancionado com coima" (Artigo 13 ${ }^{\circ}, \mathrm{n}^{\circ} 4$ ), a descrevemos pela proposição "Se alguém circular em sentido oposto, então deve ser sancionado com coima". Este uso do sintagma "dever-ser" é puramente descritivo da conexão entre infracção e sanção que a norma estabelece. No entanto, Cossio pretende que ele tenha, na proposição jurídica, ainda uma outra função, e também um outro sentido. Ele, supostamente, deve exprimir o carácter obrigatório da norma no seu todo, ou seja, terá de, auto-referencialmente, significar: "Se alguém

\footnotetext{
8 "We have ontic necessity when, for instance, something's being necessitates it to be something else, or when its being something prevents it from being something else" (Hofstadter, 1957, 603)
}

Manuscrito - Rev. Int. Fil., Campinas, v. 38, n.1, pp. 167-205, jan.-jun. 2015. 
circular..., então deve ser sancionado com coima $e$ isto é uma obrigação (um "dever-ser") para as autoridades competentes". Aqui, o dever-ser apareceria no segundo sentido de Lucia, como expressão de uma validade.

Cossio socorre-se da autoridade de Husserl para sustentar a sua análise da proposição jurídica. Argumenta que Husserl havia mostrado que, ao visar um estado de coisas através de uma expressão significativa, intentamos simultaneamente duas coisas, a saber, digamos, que "A é B", que é vivido e expressado, e que "é verdade que A é B", que é vivido mas não expressado (Cossio, 1964, 355). Mutatis mutandis, a proposição jurídica asseriria que "B deve ser, se A for", e que "é obrigatório que B seja, se a A for”. Fá-lo-ia, no entanto, expressamente, acrescentamos nós, pois a proposição jurídica deve descrever o conteúdo global da norma. Ora como não é o estudioso do direito positivo que enuncia com carácter obrigatório (sendo esta dimensão vivida mas não expressada), mas sim o legislador, a proposição jurídica deve enunciar descritivamente o duplo sentido, copulativo e obrigante, do "dever-ser". Esta é uma consequência que Cossio não parece ter em conta. Ora esta análise, assim precisada, não se pode reivindicar de um argumento de autoridade buscado em Husserl, acerca do que é vivido e expressado num juízo e do que é vivido mas não expressado nele. $\mathrm{Na}$ proposição jurídica, ambos têm de ser expressados por igual. E, nesse caso, quando descritivamente se exprime o dever-ser copulativo $e$ o dever-ser da força obrigatória da norma como um todo, a unidade semântica do dever-ser, na proposição jurídica, desintegra-se. De facto, Husserl havia mostrado - em minha opinião, correctamente - que os objectos intencionais das duas proposições são diferentes. Na primeira, estamos intencionalmente dirigidos para um estado de coisas objectivo, a saber, para o facto de que A é B, e asserimo-lo na frase declarativa (Aussagesatz) correspondente. No segundo caso, porém, estamos dirigidos para a própria proposição, para o "noema proposicional”, e 
asserimos não o estado de coisas, mas que a proposição, ela própria, é verdadeira ou falsa. Este segundo caso requer um acto intencional específico, diferente do anterior, que Husserl denomina "reflexão categorial". Assim, na proposição jurídica que descreve a norma "A é B”, o dupleto “A deve ser B” e “A é B' deve ser" está utilizando o sintagma "dever-ser" em dois sentidos diferentes, que não podem ser amalgamados, como o quer Cossio, num único enunciado da forma "se A, deve ser B", em que "deve ser" teria simultaneamente um sentido copulativo e um sentido de força obrigante da norma como um todo. Teríamos, aqui, na proposição jurídica que expressa o conteúdo da norma, um caso em tudo anómalo de um "dever-ser" auto-referencial conjugado com um "dever-ser" simplesmente copulativo.

Esta análise é, pois, pouco verosímil: o "dever-ser" torna-se polissémico, oscilando entre a matéria proposicional e a qualidade de acto, e introduz na proposição jurídica uma auto-referencialidade que não é de todo justificável. Estes dois níveis semânticos do dever-ser podem - e têm - de ser dissociados na proposição jurídica, pois referem-se, respectivamente à matéria intencional (o dever-ser copulativo) e à qualidade de acto normativo (o dever-ser que descreve a valência da própria norma como um todo). Temos, assim, de procurar uma metalinguagem para expressar o conteúdo das normas que desfaça esta amálgama ambígua. Ela teria de envolver uma conjunção de várias proposições, a saber:

(i) A norma N diz que "Quem circular, etc." $e$

(ii) N é válida no sistema jurídico tal ou tal $e$

Manuscrito - Rev. Int. Fil., Campinas, v. 38, n.1, pp. 167-205, jan.-jun. 2015. 
(iii) $\mathrm{N}$ tem força obrigatória.

\section{IV - Dever-ser e força ductiva}

O meu segundo argumento é que a qualidade de acto dos actos normativos exibe uma variabilidade tal que não é, sequer, expressável pelo sintagma verbal dever-ser, pois este está estritamente ligado à obrigação ou força coerciva, que é apenas um caso, se bem que relevante, dos modos possíveis de ducção que a qualidade normativa pode assumir.

A questão em torno da qualidade do acto normativo pode ser reformulada a partir da distinção fregeana entre "conteúdo" e "força". Um sentido proposicional, que expressa um pensamento, pode ser objecto de um acto de asserção, mas também, permanecendo o mesmo, pode dar lugar a uma pergunta de sim ou não, ou ser antecedente de um juízo hipotético. De cada vez, há um elemento idêntico, o próprio pensamento, e uma variabilidade dos modos de enunciação, que transformam esse pensamento em frases assertivas, interrogativas ou condicionais. Como o escreve em Der Gendanke,

Frases interrogativas e frases declarativas contêm os mesmos pensamentos; a frase declarativa, porém, contém qualquer coisa mais, a saber, precisamente a asserção. Também a frase interrogativa contém algo mais, a saber, uma solicitação. ${ }^{9}$

Contrariamente a estas, Frege distinguia, no mesmo passo, outras frases, como as optativas, as imperativas e rogativas, que não

9 „Fragesatz und Behauptungsatz enthalten denselben Gedanken; aber der Behauptungssatz enthält noch etwas mehr, nämlich eben die Behauptung. Auch der Fragesatz enthält etwas mehr, nämlich eine Aufforderung" (Frege, 2003, 4041).

Manuscrito - Rev. Int. Fil., Campinas, v. 38, n.1, pp. 167-205, jan.-jun. 2015. 
podiam ser consideradas "pensamentos", por o seu sentido não ser verdadeiro ou falso.

A questão fenomenológica sobre a qualidade dos actos tem uma semelhança estrutural com estas distinções fregeanas. À distinção entre conteúdo e força corresponde a distinção entre matéria e qualidade de acto; e à distinção entre frases que expressam ou não pensamentos susceptíveis de verdade ou falsidade corresponde a distinção fenomenológica entre actos objectivantes e actos fundados. A questão é, pois, onde a qualidade do acto normativo deve ser inserida: na classe dos actos objectivantes, que têm um conteúdo proposicional que pode ser objecto de um reconhecimento da sua verdade (um juízo) e de um acto de asserção, ou na classe dos actos fundados, que têm por base, mas não são actos objectivantes.

Desde cedo que os fenomenólogos recusaram a visão, vulgar no fim do século XIX e início do século XX, das normas como imperativos ou comandos acompanhados de sanção. A razão profunda para isso é a convertibilidade entre juízos e normas que assinalei atrás, ou seja, o facto de o conteúdo proposicional permanecer imutável quando passa de juízo, com força assertiva, para norma. Na verdade, o conteúdo "O Presidente nomeia o Primeiro-Ministro" tando pode dar a matéria para um acto tético como para um acto nomotético e funcionar como frase declarativa ou como norma. Muito ao contrário dos actos fundados, em que o conteúdo proposicional deve ser precedido de cláusulas como "eu desejo que...", “eu ordeno que...", e semelhantes, a convertibilidade de juízo em normas é directa, sem necessidade das cláusulas próprias dos actos fundados. Esta semelhança estrutural flagrante está, creio, na base da recusa, quer de Kaufmann, quer de Reinach, quer também de Spiegelberg, em construir a normatividade a partir da ideia de imperatividade, ou seja, como um conjunto de ordens, mesmo que essas ordens sejam entendidas impessoalmente. Isso

Manuscrito - Rev. Int. Fil., Campinas, v. 38, n.1, pp. 167-205, jan.-jun. 2015. 
significa, no idiolecto fenomenológico, que o acto normativo não é um acto fundado. À única opção que aparentemente restava deu-lhe plena expressão Carlos Cossio: dado que o acto normativo não é um acto fundado, será então um juízo, um juízo que se distingue do juízo dóxico pelo facto de a cópula consistir no "dever-ser" e não no "ser". Daí a insistência de Cossio na necessidade de uma "lógica do dever-ser", que deveria ser desenvolvida em paralelo à lógica modal alética e como irredutível a esta, na esteira de algumas intuições nucleares da lógica deôntica de von Wright, que Cossio discute expressamente (Cossio, 1964, 333 e sgs).

Como notou Paul Amselek - um teórico do direito mais recente que tem uma relação estreita com a fenomenologia -, "a ideia confusa do dever-ser não é outra coisa senão uma outra maneira de exprimir a própria estrutura da norma de modelo, de instrumento de avaliação" (Amselek, 1962, 81). O ponto de Amselek é importante. Devemos distinguir entre o conteúdo semântico das normas e a própria função do acto normativo. Quanto ao seu conteúdo, as normas podem ser permissões, obrigações ou proibições. Estes functores deônticos podem ser definidos uns em função dos outros, como von Wright o fez partindo do functor "permissão" $(1951,4)$. Mas do mesmo modo que uma norma permissiva não é, ela própria, permissiva, também uma norma que, quanto ao seu conteúdo, prescreve uma obrigação só incorrectamente poderá ser descrita por uma duplicação do functor deôntico "obrigação". Há que distinguir os dois planos. Há qualquer coisa na norma que a impõe como modelo para as condutas. Mas não podemos descrever essa função da norma como obrigação. De outro modo, teremos de, confusamente, dizer que as normas são todas obrigatórias e que, quanto ao seu conteúdo, podem exprimir obrigações, permissões ou proibições. Foi esta caracterização que se veio plasmar na doutrina de Kelsen e de Cossio do dever-ser. O paradoxo é que a norma, sendo uma obrigação, pode obrigar uma 
permissão, coisa que não tem um sentido claro e isento de ambiguidades.

Se distinguirmos a matéria proposicional das normas e a qualidade de acto normativo, podemos clarificar este ponto. Quanto ao seu conteúdo proposicional, as normas expressam ou obrigações ou permissões ou proibições. A qualidade do acto normativo, ou seja, o tipo de intencionalidade que define a consciência originariamente produtora de normas, é, porém, uma única: a norma não diz o que é, como um juízo, pelo contrário, constitui originariamente estatutos e relações jurídicas; o acto normativo também não prescreve o que deveser, como se fosse uma estrita obrigação; o acto normativo estabelece um padrão de referência para os comportamentos, que se relaciona com a liberdade dos agentes com níveis diversos de coercividade. Numa palavra, o acto normativo é um acto "ductivo" ou um acto de "ducção", palavras que, à falta de melhor, criamos directamente a partir do latim ductio, ducere. A função da norma é estatuir um padrão de referência para comportamentos possíveis e constituir originariamente os estatutos daqueles que se assumem, ou podem assumir, como sujeitos desses comportamentos. Olhando a grande variedade de normas, desde as normas morais às jurídicas, passando pelas instrumentais, pelas regras de etiqueta, e tantas outras, é fácil compreender que a vida social está perpassada por regras e códigos. E é também fácil perceber que esses padrões de referência estão longe de ter, todos eles, uma força coerciva, e que a sua função de padrão admite uma paleta bem variegada de modalidades. Seria uma opção limitadora considerar que só as normas jurídicas, com uma força coerciva e, por vezes, também sancionatória, podem ser verdadeiramente denominadas como "normas". Isso seria estreitar artificialmente o fenómeno social da normatividade.

Manuscrito - Rev. Int. Fil., Campinas, v. 38, n.1, pp. 167-205, jan.-jun. 2015. 
É, porém, uma tendência quase inexorável do pensamento jurídico considerar que as normas têm necessariamente uma força ductiva coerciva (jus cogens). Daí a tendência para as expressar como um "dever-ser", como se uma norma só pudesse ter força obrigatória. $\mathrm{Na}$ verdade, a distinção entre normas coercivas e normas não-coercivas passou, entre os clássicos, como sendo a própria linha divisória entre o Direito e a Ética. Isso pode ver-se claramente em Thomasius: a distinção entre obligatio interna e obligatio externa separava a esfera dos conselhos da razão, relativos ao decorum e ao honestum, de um lado, e a esfera do justum, do outro. Assim se apartavam as esferas da Ética e do Direito. No entanto, há normas jurídicas não estritamente coercivas. Por exemplo, os dispositivos de opt-in (a norma aplica-se se for aceite) e de opt-out (a norma não se aplica se for rejeitada), no direito europeu dos contratos, permitem falar de uma força opcional da norma, na medida em que convocam expressamente uma decisão voluntária de aceitação ou de rejeição. Também o fenómeno designado por soft law, relativo a declarações e recomendações de organismos internacionais, é claro exemplo de uma força ductiva não coerciva, mas meramente indicadora, que tem, porém, eficácia. Seria uma visão limitativa considerar o soft law como uma espécie de antecâmara de um hard law futuro. Pelo contrário, ele desempenha uma função específica, nomeadamente dando aos estados capacidade para cumprir não vinculativamente resoluções ou acordos, libertos dos mecanismos “bard” dos tratados internacionais. ${ }^{10} \mathrm{E}$ também, na ordem jurídica inter-

${ }^{10}$ Esta questão, apesar de controvertida, tem vindo a estabilizar-se em torno do reconhecimento da autonomia do soft law. Dou apenas uma abonação: "Emerging changes that have occurred in recent years has also influenced the methods and enforcement of international law. The positivist approach to law defined a norm as a law if a sanction or other type of enforcement followed it. In the international system, sovereign states use treaties, general principles of law and customary international law. The International Court of Justice recognizes these methods as a source of law and believes that judicial decisions as well as education will help implement laws. Within the last forty years, soft law, something that is either not 
na, documentos legais como pareceres do Tribunal de Contas ou decisões do Provedor de Justiça, bem como recomendações de autoridades reguladoras, não têm força coerciva para as entidades visadas, se bem que, muitas vezes, se articulem em termos de dever. Pese embora as normas jurídicas terem, na esmagadora maioria dos casos, uma força ductiva coerciva, há modulações dentro da própria esfera do Direito, de modo que força ductiva não significa eo ipso estrita coercividade. Nem tudo é coercivo no universo jurídico, do mesmo modo que nem todas as normas estão acompanhadas de sanção. Esta ductilidade do que chamamos "força ductiva da norma" foi bem exposta pelo jurista Cédric Grouiler. Vale a pena citar as suas palavras:

A função dada à norma jurídica [é] fornecer uma referência para a organização das relações sociais. Ora esta função é ocultada pela abordagem imperativista, focada nessa especificidade que o Direito teria de se impor unilateralmente e de se apoiar num aparelho coactivo ligado ao poder. ... O ponto de vista imperativista não só adopta uma posição dogmática, que o obriga a contorções teóricas a respeito das normas permissivas, mas restringe e obscurece o que se deve entender por força normativa: a exclusão do soft law mostra como a noção de normatividade está desnaturada, pois não mais remete, como a etimologia da palavra norma o ensina, para essa aptidão para constituir um modelo, uma referência, mas está consubstancialmente ligada à coacção. Só é norma o que coage. Do mesmo modo, parece que foi feita uma associação abusiva da normatividade à juridicidade: pretensamente não-normativo, o soft law é lançado para fora do campo jurídico. $^{11}$

year or not only a law, has been a major influence in international law. The United Nations system has used soft law to create and establish declarations, codes of conduct and guidelines. Non-governmental organizations have also used soft law to create resolutions and other statements. Although soft laws lack enforceability, they have normative weight in the international system. International environmental law has appeared to blur the use and difference between soft law and hard law in order to face new trends in the international system" (Buriel et alia, 2004).

11 « La fonction assigné à la norme juridique [est de] fournir référence pour l'organisation des rapports sociaux. Or, cette fonction est occultée dans l'approche

Manuscrito - Rev. Int. Fil., Campinas, v. 38, n.1, pp. 167-205, jan.-jun. 2015. 
Neste caso, há mais uma vez um estreito paralelismo com o juízo, ou seja, com a esfera dos actos téticos. Para estes últimos, a qualidade posicional pode ir da existência à não existência, passando por graus intermédios como a possibilidade, a verosimilhança, e outros. A força ductiva também se deixa modular de um modo estruturalmente semelhante às modalidades dóxicas do juízo. Chamemos-lhes "modalidades nómicas". Normas há cuja força ductiva é a coerção, mas outras normas há que cuja força ductiva é a do conselho ou da recomendação. Mesmo a força ductiva nula é uma realidade, à semelhança do acto tético da negação, pese embora o aparente paradoxo de se falar de uma norma cuja função de referência para os comportamentos seja inexistente. No entanto, o caso de uma norma revogada por outra norma (seja derrogação ou ab-rogação) é um exemplo disso. A norma revogada continua a existir como objecto da norma revogatória, ela não desaparece do universo jurídico; no entanto, a sua força ductiva é-lhe cancelada, total ou parcialmente, pela norma revogatória.

Para condensar este ponto direi que entre actos téticos e nomotéticos há um estrito paralelismo, que induz a considerá-los como conjuntos complementares de actos fundantes. Os objectos de uma ontologia da natureza são descritos por actos téticos; os objectos de

impérativiste, focalisé sur cette spécificité qu'aurai le droit à s'imposer unilatéralement et à s'appuyer sur un appareil coercitif lié au pouvoir. ... Non seulement de point de vue impérativiste adopte une posture dogmatique qui oblige à des contorsions théoriques s'agissant des normes permissives, mais il restreint et obscurcit ce qu'il faut entendre par force normative : l'exclusion du soft law montre combien la notion de normativité est dénaturée, qu'elle ne renvoie plus, comme l'étymologie du mot norme l'enseigne, à cette aptitude à constituer un modèle, une référence, mais est consubstantiellement liée à la contrainte. N'est normatif que ce qui contraint. De même, il semble que soit opéré une association abusive de la normativité à la juridicité : prétendument non normatif, le soft law est rejeté hors du champ du juridique » (Groulier, 2009, 201).

Manuscrito - Rev. Int. Fil., Campinas, v. 38, n.1, pp. 167-205, jan.-jun. 2015. 
uma ontologia do mundo social são originariamente constituídos por normas. Relativamente à qualidade, a força ductiva é susceptível de modulações, do mesmo modo que a qualidade tética dos actos objectivantes o é. O que diferencia juízos e normas e os torna classes complementares, irredutíveis, tem que ver uma característica fundamental: enquanto os juízos podem ser verdadeiros ou falsos, as normas são ou válidas ou inválidas. A razão profunda para não reconduzir validade a verdade e para não fazer equivaler juízos a normas (substituindo a cópula, segundo Cossio), terá talvez que ver com aquilo que Austin e Searle denominaram como "direcção de ajustamento" (direction of fit): um juízo é verdadeiro na medida em que descreve um estado de coisas pré-existente à linguagem; a norma, pelo seu lado, é válida na medida em que torna possível que um estado de coisas ocorra no mundo por força da pré-existência do acto normativo. Os juízos só são verdadeiros se certas coisas lhes pré-existirem; certas coisas só existem por força das normas que as estatuem.

Pondo por um momento de parte a fenomenologia dos actos e concentrando-nos apenas no plano dos signos expressivos, bem poderíamos fixar a diferença entre frases declarativas e frases normativas, usando uma metalinguagem liberta dos equívocos do "dever-ser", expandindo e modificando o esquema de Tarski do seguinte modo:

Se "A neve é branca" é verdade sse a neve é branca,

então "A neve é branca" é uma frase declarativa;

Se o Presidente nomeia o $1^{\circ}$ Ministro sse "O Presidente nomeia o $1^{\circ}$ Ministro" é válido,

então "O Presidente nomeia o $1^{\circ}$ Ministro" é uma frase normativa.

Manuscrito - Rev. Int. Fil., Campinas, v. 38, n.1, pp. 167-205, jan.-jun. 2015. 


\section{Em jeito de conclusão}

Para tornar bem patentes os pontos essenciais de minha argumentação, direi, em resumo, o seguinte:

$1^{\circ} \mathrm{O}$ fenómeno normativo é um dos elementos basilares da ontologia social: os objectos do mundo social são originariamente constituídos por normações instituidoras e não existiriam sem estes actos doadores de sentido - uma tese toda ela contra o essencialismo de Reinach;

$2^{\circ}$ Os actos normativos são irredutíveis a actos objectivantes, seja porque não os contêm na sua base, seja porque a forma normativa não é derivável quer de juízos teóricos, quer de juízos axiológicos, quer da conjugação de ambos, se bem que, obviamente, o acto normativo não se faça em abstração relativamente a conhecimentos teóricos e a juízos de valor - uma tese que pretende reavaliar criticamente algumas intuições bem conhecidas de Husserl;

$4^{\circ}$ As normas podem ser expressas em proposições que descrevem o seu sentido e força obrigante, mas essas proposições não deveriam ser articuladas pelo sintagma "dever-ser", dado que ele, nesse caso, é chamado a exprimir a matéria intencional da norma (que, inclusivamente, pode não ser uma obrigação) e, simultaneamente, a força ductiva da norma (que, também, pode não ser a estrita coerção), pelo que essa formulação é ao mesmo tempo geradora de incorrecções e de ambiguidades - uma tese contra o main stream da literatura especializada.

$5^{\circ}$ A mais correcta expressão descritiva de uma norma seria numa metalinguagem que dissociasse a sua matéria proposicional e a sua qualidade ou força ductiva; 
$6^{\circ}$ A força ductiva das normas constitui uma paleta bem variegada, que pode ir da coerção ao simples conselho, pelo que é um enviesamento empobrecedor conceber toda norma como um comando e como imposição de uma estrita obrigação.

Uma análise fenomenológica da força ductiva levar-nos-ia até o cerne de uma ontologia do mundo social. Esse não foi, porém, o objectivo deste trabalho.

\section{REFERÊNCIAS}

AMSELEK, P. Perspectives critiques d'une réflexion épistémologique sur la théorie du droit. Paris : LGDJ, 1962.

BURIEL, L.; HWANG, C. \& SUGANTA, A. "Baseline Statement: Strengthening The System International Law". In Environmental International Law. Geoffrey Wandesforde-Smith (Coord.): UC Davis/University of North London, 2004.

FREGE, G. Logische Untersuchungen. Göttingen: Vandenhoeck \& Riprecht, 2003.

CONTE, A. "Hans Kelsen Deontics". In S. Paulson and B. Litschewski Paulson (eds.) Normativity and Norms. Critical Perspectives on Kelsian Themes. Oxford, New York: Clarendon Press, (1998).

COSSIO, C. La Teoría Egológica del Derecho y el Concepto Jurídico de Libertad. Buenos Aires: Abeledo-Perrot, 1964.

GROULIER, C. La distinction de la force contraignante et de la force obligatoire des normes juridiques. Pour une approche duale de la

Manuscrito - Rev. Int. Fil., Campinas, v. 38, n.1, pp. 167-205, jan.-jun. 2015. 
force normative. in $L a$ force normative. Naissance d'un concept. Catherine Thibierge (ed.). Paris: LGDJ, 2009.

HOFSTADTER, A. "Six Necessities". In The Journal of Philosophy, 54, pp. 597-613, 1957.

HUSSERL, E. Logische Untersuchungen. Erster Teil. Prolegomena zur reinen Logik. The Hague: Martinus Nijhoff, 1975.

- - Ideen zu einer reinen Phänomenologie und phänomenologischen Philosophie. Erstes Buch: Allgemeine Einführung in die reine Phänomenologie 1. Halbband. The Hague: Martinus Nijhoff, 1977.

- Logische Untersuchungen. Zweiter Teil. Untersuchungen zur Phänomenologie und Theorie der Erkenntnis. The Hague: Martinus Nijhoff, 1884.

KAUFMANN, F. Logik und Rechtswissenschaft. Grundriss eines Systems der reinen Rechtslehre. Tübingen: Verlags J. C. B. Mohr, 1922.

KELSEN, H. Essays in Legal and Moral Philosophy. D. Reidel Publishing Company: Dordrecht-Holland/Boston-USA, 1973.

LUCIA, P. "Tre specie di dovere eidetico. Un'analisi ontologica“. In Paolo de Lucia (ed.) Ontologia sociale. Potere deontico e regole constitutive. Macerata: Quodlibet, (2003).

LUCIA, P. Ontologia sociale. Potere deontico e regole constitutive. Macerata: Quodlibet, 2003.

PAULSON, S. and PAULSON, B. L. Normativity and Norms. Critical Perspectives on Kelsian Themes. Oxford, New York: Clarendon Press, 1998.

MULLIGAN K. Speech Act and Sachverhalt. Reinach and the Foundations of Realist Phenomenology. Dordrecht \& Boston: Martinus Nijhoff, 1987. 
REINACH, A. Sämtliche Werke I. (K. Schuhmann and B. Smith eds.). München: Philosophia Verlag, 1989.

SMITH, B. "Adolf Reinach 1883-1917”, in Speech Act and Sachverhalt. Reinach and the Foundations of Realist Phenomenology. Kevin Mulligan (ed.), Dordrecht \& Boston: Martinus Nijhoff, (1987).

SPIEGELBERG, H. Gesetz und Sittengeset\%: Srukturanalytische und historishe Vorstudien zur einer gesetzfreien Ethik. Zurich: Max Niehans Verlag, 1935.

THIBIERGE, C. La force normative. Naissance d'un concept. Paris: LGDJ, 2009.

WRIGHT, G V. "Deontic Logic”. Mind. Vol. LX, n² 237, 1951.

WANDESFORDE-SMITH, G. Environmental International Law. UC Davis/University of North London, 2004. 
